\title{
Crear un cuento en clase
}

\section{Arsenio SANZ RIVERA}

\section{Introducción : Situación y objetivos.}

Después de poco más de un año de estudiar y repetir esquemas gramaticales, frases modelo, y hacer múltiples ejercicios, cuando llegan las vacaciones de verano, al estudiante le queda la opción de viajar al extranjero, conocer "in situ" otra cultura, otros modos de vida y probar lo aprendido, o quedarse en su país esperando a que las clases continúen, sin arriesgarse a nada. Después del verano el curso se reanuda y cada estudiante ha tenido una experiencia distinta, en el extranjero o en casa, algo que sin duda determina la participación en el aula de una manera más o menos activa. Las clases siguen su curso normal, se suceden las explicaciones gramaticales, situaciones modelo, (que algunos ya conocen por experiencia propia) más ejercicios gramaticales y poco a poco aquel interés primario por conocer, por palpar directamente otra forma de vida en la lengua extranjera, va disminuyendo progresivamente ante el aluvión de nuevos conocimientos que los estudiantes tienen que ir asimilando.

Partiendo de la idea de que cada clase es diferente, como lo es cada estudiante o cada profesor, a la vuelta de las vacaciones en el verano del 1998, en la Universidad de Estudios Extranjeros Kanda, con los estudiantes de segundo año del departamento de español, nos propusimos crear dentro del curso un apartado diferente, algo que podríamos definir como taller literario. Una experiencia innovadora en la que el enseñante preocupado por hacer más apetecible y fácil de digerir ese trozo del pastel del español que ofrece a los alumnos, decidió dejar de lado el libro de texto (sólo como referencia en caso de duda) y dar un cambio en la orientación y el contenido de la clase.

Uno de los objetivos era desarrollar la escritura, una de las cuatro destrezas básicas en el aprendizaje de una lengua y requerida en exámenes de prestigio internacional como el D.E.L.E. ${ }^{1}$. Nuestra intención en esta nueva experiencia no 
era ofrecer al estudiante un sin-fin de cartas modelo a imitar, ni tampoco presentarle una serie de lecturas, quizás muy interesantes desde el punto de vista linguístico o literario, pero fuera de su interés más inmediato como es el uso de lo aprendido. Para ello con el firme propósito de que en todo momento los estudiantes fueran los protagonistas y pudieran apreciar que los conocimientos adquiridos eran muchos y realmente podían dar fruto, decidimos crear un cuento.

Un taller literario donde la creatividad personal o en grupo y la imaginación junto a la libertad de poder moverse en un mundo creado por ellos mismos, les iniciara en la árdua tarea de componer-expresarse-reflexionar-sentir para terminar disfrutando de su trabajo.

\section{Proceso : Repaso y desarrollo progresivo de las destrezas.}

Antes de proceder a la composición del producto final se hacía necesario repasar, afianzar las destrezas obtenidas, aumentarlas y finalmente poder desarrollarlas.

Tomamos como referencia algunas de las propuestas que el Profesor Cassany2) plantea como los valores necesarios para crear un texto eficaz; esto es la gramaticalidad del escrito, es decir: el corpus de la gramática normativa (ortografía, sintaxis, semántica, etc.) y el conjunto de reglas linguísticas que permiten construir oraciones gramaticales comprensibles para los parlantes de la lengua meta, en este caso el español. Decidimos llevar a cabo, gradualmente, una serie de ejercicios donde el alumno no tenía ningún ejemplo a imitar ni se encontraba ante un problema de respuestas cerradas con una única solución. Solamente podía recurrir a su conocimiento previo del sistema y hacer un uso correcto de él.

Ejemplo 1)

\section{Mi pueblo desde}

Desde todo se ve distinto, parece otro

Ahora puedo verlo igual que. ,desde el cielo.

Mi pueblo son muchas casas. colocadas $\sin$ Casas ..y...................,algunas con patio y otras ,pero todas con En las afueras del pueblo hay. que ya no funciona, donde los chicos van a a menudo, cerca hay un ,el Manzanares, 
En un segundo nivel de trabajo, después de haber realizado el ejercicio en clase con numerosos ejemplos y explicaciones detalladas, el texto se hace más complicado. Se pide al estudiante que ofrezca descripciones de los protagonistas y los entornos o situaciones en los cuales la acción se desarrolla. Los aprendientes manejaban unas indicaciones para crear la biografía de un personaje imaginario, elaborando el texto a través de un producto verbal linealizado, donde todas las proposiciones adquirían coherencia y cohesión dentro del conjunto.

Ejemplo 2)

Biografía de ..........(ponle tú el nombre)

nació (dónde y cuándo).

(habla de su familia, trabajo de los padres).

(¿cómo era su carácter?)

Estudió .en.

(¿cómo era su vida de estudiante, trabajaba, tenía novia, amigos?)

Finalmente en (terminó los estudios, empezó a trabajar, dónde)

(¿por qué es famoso?, ¿alguien influyó en él?, ¿dónde lo conoció?)

(fechas más importantes en su vida).

(se casó, tuvo hijos)

(¿cómo y dónde murió?). 
Conviene resaltar que a estas alturas los estudiantes ya trabajan en equipos de dos o tres miembros, que el producto final es el trabajo de todos y antes de entregarlo es necesario hacer varias revisiones del trabajo, el cual posteriormente será presentado, leido a los demás compañeros. Es en este momento, cuando el lector-autor del texto verbaliza sus pensamientos, mostrando sus procesos cognitivos de la composición escrita y ofreciendo otras alternativas a sus compañeros, éstos actuan como oyentes-aprendientes, aceptando el mensaje y comparándolo con su trabajo lo cual permite hacer una mejora en la calidad de los escritos fomentando el entusiasmo y la participación en el aula.

Una vez que el estudiante estaba familiarizado con la llamada función epistémica de la escritura, es decir, se había acostumbrado a través de la composición escrita a hacer un uso más creativo y/o artístico de la lengua, e incluso a manejar y modificar coherentemente un texto y a manipular la información (función instrumental) desarrollando con ello una conducta de composición más completa y personal, decidimos atender a otros aspectos que posteriormente serían necesarios.

Como nuestro propósito final era una creación literaria, lo inmediato era acercarnos a los textos que nos pudieran servir de ayuda: En nuestro caso los cuentos. Para ello tradujimos algunos cuentos populares japoneses: Okiku no tatari, kubi o nakushita akanbo, etc. Narraciones breves pero de pleno valor para nuestro trabajo. A través del proceso de traducción escrita los aprendientes empezaban a reconocer las funciones específicas de la escritura, (comunicativa, ejecutiva, epistémica e instrumental) tomando contacto con las relaciones sintagmáticas del texto y decidiendo cómo trasladar a la lengua meta, no una frase sino una insinuación del protagonista, cómo y cuándo hacer uso de determinadas conjugaciones: el pretérito imperfecto para las descripciones, el uso del subjuntivo ante una suposición o un deseo de determinado personaje, el potencial ante una remota posibilidad condicionada o las frases cortas; breves y contundentes en las cuales la acción principal se tornaba rápida y directa, envolviendo a los protagonistas en un torbellino dentro del relato.

En ocasiones los aprendientes se veían en la necesidad de hacer el papel de 
narrador dentro de la propia historia, incluyendo diálogos con los personajes y breves monólogos donde su "yo" interior reflexionaba, sacaba conclusiones y volvía a tomar el hilo del relato en los hechos pasados o en el presente narrador. Esta experiencia también sirvió para hacer ver a los aprendientes que crear un texto no era sólo manipular información y respetar los principios gramaticales de la lengua, sino que para conseguir un texto interesante, hacía falta prestar especial atención a lo que podríamos llamar sus pilares básicos, su sostenimiento. Entre todos descubrimos que para que haya una historia y para que ésta sea inteligible hacía falta una coherencia elemental en ese conjunto de acciones realizadas, siendo el orden cronológico el más simple. "con el perdón del nuevo Rey, el noble exiliado regresa a la Corte,... de nuevo se relaciona con sus antiguos camaradas, y vuelve a la vida anterior de vicio y jolgorio,... pero esta vez sus objetivos son demasiado ambiciosos $y$..."3). Es una historia resumida, tal y como la contaría un niño; sucesión de hechos entre los que el autor debe establecer relaciones lógicas. El creador del texto no sólo relacionaba los episodios, también debía animar a sus personajes, describir su cuadro espacial y el tiempo en el que se desarrollaba la acción.

La planificación del texto, elementos básicos para su presentación en público:

Atendía a varios puntos esenciales; lo primero era tomar conciencia comunicativa de a quién iba dirigido el escrito. Después, dentro del discurso, qué función del lenguaje: expresiva, informativa o apelativa, etc, debía destacarse y en qué momento de la narración.

Dadas las características del público receptor (nosotros mismos, la clase, los compañeros) el tipo de discurso a utilizar no presentó ningún problema. El texto debía ser fácil de entender por los oyentes y desenvolverse en un lenguaje familiar, manifestando valoraciones y emociones del hablante, pero sin pretensiones literarias. Para la lectura en clase, decidimos tener en cuenta los siguientes puntos que consideramos básicos:

-Buena memoria: el texto se debía contar mirando al público sin papel ni apuntes, con el cuerpo libre para poder gesticular y hacer más comprensible y expresivo el relato. 
-Fluidez en la narracion: el relato debía mantenerse vivo para transmitir al auditorio, no sólo un mensaje verbal, sino también sensaciones de emoción, alegr ía, cansancio, incertidumbre, etc, que hicieran a los oyentes participar en el relato imaginándose posibles situaciones futuras, adelantándose a la narración.

-Voz flexible: con una dicción correcta: adecuándose a los diferentes personajes: (niña, abuelo, borracho, guerrero...) y al estado emocional de los mismos (preocupación, miedo, alegría, enfado, esperanza...)

-Serenidad y confianza en sí mismo: para poder llevar a cabo la representación del relato y poder sortear cualquier eventualidad (nervios, olvido momentáneo, despiste, etc.)

Hacer un reconocimiento de las diversas funciones del lenguaje para luego poder usarlas correctamente en el trabajo final, nos llevó a leer e interpretar anuncios del periódico, opiniones y por supuesto, poesía; de García Lorca, Juan Ramón Jiménez, Antonio Machado, etc que nos demostraron cómo se hacía uso del discurso expresivo literario; viendo a su vez en qué consistían ciertas figuras como: metáfora, comparación y repeticiones con fines expresivos: tal y como aparece en el comienzo de uno de nuestros cuentos:

"En aquel jardin había muchas flores; flores hermosas, flores ricas en colores, que florecían con amenidad. Como si fuera el campo del cosmos. En este lugar vivía un viejo solo..."4)

Hipérbatón, personificación, etc... son algunas otras figuras literarias que se pueden encontrar en estos relatos:

"...de repente Torre se cayó al estanque. Cuando Alfil iba a zambullirse para socorrerlo, la superficie del agua comenzó a brillar. De repente Alfil vio algo subiendo rapidamente desde el fondo. Alfil se quedó contemplando eso y vio que era un gran siluro con manos y pies como los hombres. El gran siluro se levantó orgulloso sobre la superficie brillante y Alfil le dijo:

- ¿Quién eres?

- Me llamo Peón y soy el dueño del estanque encantado." 5)

\section{Trabajo en equipo}

Definir la estructura del cuento formaba parte del proceso de composición, generar nuevas ideas, organizarlas y poderlas enlazar en un conjunto coherente era 
algo que habíamos estado realizando a través de los diversos ejercicios y la práctica de la traducción nos ayudó a consolidar. Para ello los estudiantes revisaban el texto evaluando diversas versiones donde se comparaba el estado del trabajo escrito antes y después para obtener así una visión más clara de lo que podia llegar a ser el texto final. Se utilizaron numerosos borradores de los cuales se recuperaba el léxico más adecuado, reelaborando el producto y definiendo cuál sería el contenido y cómo expresarlo. Una parte importante de este proceso de autocorrección, consistía en dejar trabajar solos a los estudiantes siendo ellos quienes dirigían su propio trabajo de una manera dinámica, activa y continuada. Actos que por otra parte les conferían una mayor confianza personal siendo capaces de resolver sus dudas iniciales a través de la comparación de textos y la opinion de otros compañeros.

Una vez realizado lo que podríamos llamar el borrador del texto definitivo, éste era presentado por primera vez al profesor quien, respetando siempre la originalidad del texto y a los autores, hacía los comentarios oportunos atendiendo unicamente a su gramaticalidad, coherencia, adecuación y demás valores necesarios que permitieran identificar el trabajo como un texto con sentido pleno.

\section{Conclusiones:}

A modo de epílogo podemos señalar las siguientes consideraciones.

1. Con este tipo de ejercicios que el estudiante debía completar correctamente, hacía uso de sus conocimientos adquiridos de una manera libre y natural, repasaba la gramática de un modo inconsciente (relaciones morfosintácticas; verbos, adjetivos, etc..) y además el aprendiente, se veía abocado a dotar de coherencia el escrito, que como se puede observar (páginas 2,3) tiene múltiples contestaciones válidas; el único limite, si lo hubiera, sería la imaginación.

2. Al mismo tiempo, el aprendiente comenzaba a utilizar el texto para manipular información: pudiendo ampliar o reducir el mensaje escrito y desarrollando nuevas ideas que le ayudaban a introducirse en el mundo de la composición sin pensar en dificultades añadidas, al mismo tiempo que disfrutaba con su trabajo.

3. Dirigir ellos mismos (los estudiantes) su proceso de creación les permitía además, tener conciencia sobre su trabajo autorregulándose personalmente, sin 
posibilidad de que la explicación o consejo del profesor pudiera frenar el impulso creativo de nadie.

De lo anteriormente expuesto deducimos que la creación de este tipo de talleres literarios, no sólo ofrecen al estudiante una libertad insospechada de aprender y disfrutar de su estudio, al mismo tiempo, les anima a crear, imaginar en la lengua extranjera sin frenar su desarrollo con complicadas reglas.

También llegamos a la conclusión de que la participación y el ambiente extraordinarios en el taller que aquí se menciona, se debía sin duda, a la propia autoestima de los estudiantes y a la confianza en sí mismos que fueron aumentando progresivamente.

El resultado final de todo este trabajo y la eficacia del método empleado, frutos ambos del esfuerzo común, se resumen y demuestran en un pequeño librito que hemos titulado Cuentos de Kanda . $^{6}$ En este texto se recogen los ocho cuentos en español, escritos integramente por estudiantes japoneses en su segundo año en la universidad. En dicho libro quedan patentes el buen hacer e ilusión de los estudiantes que sin duda alguna, recompensan tantas horas frente al ordenador y el sueño perdido.

\section{Notas}

1) Examen reconocido por el M.E.C.D. que administra el Instituto Cervantes y a su vez, elabora y corrige la Universidad de Salamanca.

2) Cassany Daniel. La composición escrita. Centro de Estudios Hispánicos de la Universidad Sofía, Tokyo, 1996.(pp, 18, 19)

3) Moscardó Roca, Juan Pedro, (1999) Como en humo aquel fuego. Ediciones Apóstrofe S.L. Madrid. (pp. 17, 18)

4) Koike, S., Setoguchi, Ch. y Yamada, S. Contigo eternamente, cógeme en el jardin del cosmos. (Cuentos de Kanda p. 1.)

5) Nakajo, K., Tonouchi, T. y Watanabe, K. El estanque encantado (Cuentos de Kanda pp. 13, 14)

6) El libro fue presentado por el autor de este trabajo tras la lectura de su conferencia en la universidad Tenri, en Nara, durante el Congreso de Hispanistas allí celebrado los días 27 y 28 de octubre de 2001 . 


\section{Bibliografia:}

Arnal, Carmen, y Ruíz de Garibay, Aracelí (1966), Español por destrezas. Escribe en español. Sociedad General Española de Librería S.A., Madrid,

Benito Lobo, José A., y Fernández Vizoso, Martin (1996), El comentario de textos. Asimilación y sentido crítico. Edinumen, 4 edición, Madrid.

Camarero, Manuel, (1998) Introducción al comentario de textos. Castalia, Madrid.

Cassany, Daniel, (1996) La composición escrita. Centro de Estudios Hispánicos de la Universidad Sofía, Tokyo.

Ferreras, Juan Ignacio, (1973) Los onigenes de la novela decimonónica.. Taurus Ediciones, Madrid.

Girón Alconchel, José Luís, (1993) Introducción a la explicación linguistica de textos. Edinumen, 3 edicion, Madrid.

Guido, María R., y López Kopusar, Ana M., (1984) Didáctica de la Lengua.. Editorial El Ateneo, Buenos Aires.

Hernández, Guillermo, (1990) Análisis Gramatical.. Sociedad General Española de Librería S.A. Madrid.

Lázaro Carreter, Fernando, y Correa Calderón, Evaristo, (1980) Cómo se comenta un texto literario. Cátedra, 18 edición, Madrid.

Martínez Bonati, Félix, (1972) La estructura de la obra literaria. Seix Barral, Barcelona.

Moscardó Roca, Juan Pedro, (1999) Como en humo aquel fuego. Ediciones Apóstrofe S.L. Madrid.

Muñoz Alonso, Mariano, (1972, traducción) Enseñanza de idiomas e información cultural. Editorial Fragua, Madrid. Título original: Verlee, Leon, Enseignement des langues et information culturelle.

Sullá, Enric, (1975, traducción y notas) La novela. Título original: L'univers du roman. R. Bourneuf, R. Ouellet. Editorial Ariel, Barcelona. 


\section{〈Resumen〉}

\section{"Crear un cuento en clase"}

\section{Arsenio, SANZ RIVERA}

En el presente trabajo se comenta la experiencia de un taller literario en la clase de español con los estudiantes de segundo año. Alejado del clásico enfoque gramatical el profesor decidió cambiar la orientación y el contenido del curso para dar paso a un enfoque más comunicativo donde los estudiantes pudieran hacer uso inmediato de los conocimientos adquiridos. De este modo, tras la práctica de variados ejercicios donde el estudiante aprende a utilizar, ampliar o minimizar la información, el mismo aprendiente comenzará a desarrollar nuevos conocimientos y aumentar su capacidad creativa. Después, en grupos de dos o tres personas, valorando las diversas ideas y opiniones, seleccionando material y autocorrigiendo su propio trabajo escrito, a través de un largo proceso, los estudiantes llegarán al trabajo final que consistía en escribir un cuento en español. 